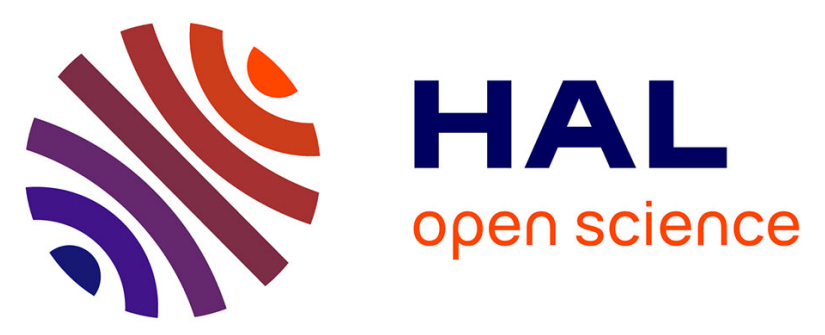

\title{
Range shifts of native and invasive trees exacerbate the impact of climate change on epiphyte distribution: The case of lung lichen and black locust in Italy
}

Juri Nascimbene, Renato Benesperi, Gabriele Casazza, Alessandro Chiarucci, Paolo Giordani

\section{To cite this version:}

Juri Nascimbene, Renato Benesperi, Gabriele Casazza, Alessandro Chiarucci, Paolo Giordani. Range shifts of native and invasive trees exacerbate the impact of climate change on epiphyte distribution: The case of lung lichen and black locust in Italy. Science of the Total Environment, 2020, 735, pp.139537. 10.1016/j.scitotenv.2020.139537 . hal-02943403

\section{HAL Id: hal-02943403 \\ https://hal-amu.archives-ouvertes.fr/hal-02943403}

Submitted on 19 Sep 2020

HAL is a multi-disciplinary open access archive for the deposit and dissemination of scientific research documents, whether they are published or not. The documents may come from teaching and research institutions in France or abroad, or from public or private research centers.
L'archive ouverte pluridisciplinaire HAL, est destinée au dépôt et à la diffusion de documents scientifiques de niveau recherche, publiés ou non, émanant des établissements d'enseignement et de recherche français ou étrangers, des laboratoires publics ou privés. 
S0048-9697(20)33054-0

https://doi.org/10.1016/j.scitotenv.2020.139537

Received date: $\quad 13$ March 2020

Revised date: $\quad 7$ May 2020

Accepted date: $\quad 17$ May 2020 
Range shifts of native and invasive trees exacerbate the impact of climate change on epiphyte distribution: the case of lung lichen and black locust in Italy

Juri Nascimbene $^{1}$, Renato Benesperi ${ }^{2 *}$, Gabriele Casazza $^{3}$, Alessandro Chiarucci ${ }^{1}$, Paolo Giordani ${ }^{4}$

${ }^{1}$ Department of Biological, Geological and Environmental Sciences, University of Bologna, Bologna, Italy

${ }^{2}$ Department of Biology, University of Firenze, Firenze, Italy

${ }^{3}$ IMBE, Aix Marseille Université, Avignon Université, CNRS, IRD, IMBE. Technopôle de l'Arbois-Méditerranée, Aix-en-Provence, France

${ }^{4}$ Department of Pharmacy, University of Genova, Genova, Italy

* Corresponding author at: renato.benesperi@unifi.it 


\begin{abstract}
While changing climatic conditions may directly impact species distribution ranges, indirect effects related to altered biotic interactions may exacerbate range shifts. This situation fully applies to epiphytic lichens that are sensitive to climatic factors and strongly depend on substrate occurrence and features for their dispersal and establishment. In this work, we modelled the climatic suitability across Italy under current and future climate of the forest species Lobaria pulmonaria, the lung lichen. Comparatively, we modelled the suitability of its main tree species in Italy, as well as that of the alien tree Robinia pseudoacacia, black locust, whose spread may cause the decline of many forest lichen species. Our results support the view that climate change may cause range shifts of epiphytes by altering the spatial pattern of their climatic suitability (direct effect) and simultaneously causing range shifts of their host-tree species (indirect effect). This phenomenon seems to be emphasized by the invasion of alien trees, as in the case of black locust, that may replace native host tree species. Results indicate that a reduction of the habitat suitability of the lung lichen across Italy should be expected in the face of climate change and that this is coupled with a loss of suitable substrate. This situation seems to be determined by two main processes that act simultaneously: 1) a partial reduction of the spatial overlap between the climatic niche of the lung lichen and that of its host tree species, and 2) the invasion of native woods by black locust. The case of lung lichen and black locust in Italy highlights that epiphytes are prone to both direct and indirect effects of climate change. The invasion of alien trees may have consequences that are still poorly evaluated for epiphytes.
\end{abstract}

Key words: alien trees, epiphytic lichens, lichen-tree range decoupling, Lobaria pulmonaria, range shifts, Robinia pseudoacacia

\title{
1. Introduction
}


Rapid climate change, driven by anomalous anthropogenic $\mathrm{CO}_{2}$ emission, is increasingly threatening biodiversity with multiple effects (Bellard et al., 2012; Cameron et al., 2004), including distributional shifts that reflect the attempt of the species to track their suitable conditions (Dyderski et al., 2018; Thurm et al., 2018). However, while changing climatic conditions may directly impact species distribution ranges (Parmesan \& Yohe, 2003; Casazza et al., 2014; Kun \& Gègout, 2019), indirect effects that could be related to altered biotic interactions potentially exacerbate species range shifts (Van der Putten et al., 2010; HilleRisLambers et al., 2013). This could be the case of those organisms whose dispersal and establishment depend on both climatic conditions and the occurrence of other species that are indispensable for providing their habitat. This situation fully applies to epiphytic lichens that are sensitive to climatic factors and strongly depend on substrate occurrence and features for their dispersal and establishment. A simultaneous loss of climatic suitability and habitat availability may exacerbate species range reduction.

Epiphytic lichens are a diverse and functionally important component of the forest biota (Nascimbene et al., 2019; van Stan and Pypker, 2015; Zedda and Rambold, 2015). They are poikilohidric organisms whose ecophysiological performance strongly depends on external environmental conditions (Insarov et al., 2002; Gauslaa, 2014; Gauslaa et al., 2006). In particular, water availability and temperature regulate photosynthetic and respiratory activities (Schroeter, et al., 2000), thus influencing lichen growth rates. At the biogeographic scale, this is reflected in climate-driven species distribution patterns (Marini et al., 2011; Nascimbene et al., 2016). However, besides climatic conditions, chemical-physical features of the substrate (e.g. bark pH, bark stability, roughness, water holding capacity) are among the most important drivers of epiphytic lichen distribution at the local scale (Fritz et al., 2009; Jüriado et al., 2009; Lewis \& Ellis., 2011; McDonald et al., 2017), resulting in local species sorting into communities that are influenced by tree species composition (Nascimbene et al., 2009, Nascimbene et al., 2013; Rubio-Salcedo et al., 2015). Under these circumstances, climate change is expected to strongly influence the distribution 
of these organisms due to altered climatic suitability (direct effect) and range shifts of their host-tree species (indirect effect).

To test this general hypothesis, (1) we modelled the current and predicted distribution of the climatic suitability of the mainly temperate species Lobaria pulmonaria (L.) Hoffm., the lung lichen, across Italy. This region is characterized by a large elevation $(0-4800 \mathrm{~m})$ and latitudinal $\left(35^{\circ}-47^{\circ}\right)$ gradient and the lung lichen almost reaches here the southern limits of its distribution range. These are optimal conditions to test the direct and indirect impacts of climate change on an epiphytic, poikilohydric organism. Due to its easy identification and its sensitiveness to both anthropogenic (i.e. air pollution, forest management) and climatic factors (Benesperi et al., 2018; Nascimbene et al., 2016; Merinero et al., 2014; Paoli et al., 2019), in the last decades a large amount of information has accumulated on its ecology and biogeography in comparison to other lichen species (e.g. Widmer et al., 2012; Nascimbene et al., 2013; e.g. Otalora et al., 2015). This provided the basis for considering the lung lichen a candidate model species to explore the response of epiphytic lichens to multiple factors (Giordani et al., 2012). Simultaneously (2), we modelled the current and future distribution of the main tree species that host this lichen in Italy (i.e. Quercus ilex L., Q. pubescens Willd., Q. cerris L., Castanea sativa Mill., and Fagus sylvatica L.; Nascimbene et al., 2013), as well as that of the alien tree Robinia pseudoacacia L., black locust, that is one of their most competing species in a climate change scenario (Kleinbauer et al., 2010; Thurm et al., 2018; Nadal-Sala et al., 2019; Vítková, 2017, 2020). Black locust is among the most invasive species in Europe (Richardson \& Rejmánek, 2011) and recent studies have shown that the substitution of native trees with black locust may cause diversity loss of epiphytic lichens and the decline of many forest species, as in the case of the lung lichen (Nascimbene et al., 2012; Nascimbene et al., 2015).

In this framework, we specifically hypothesize (a) a reduction of the habitat suitability of the lung lichen across Italy due to climate change that (b) is coupled with a co-reduction of the range of its native host tree species. This phenomenon may imply (c) a partial reduction of the climatic niche 
overlap between the epiphyte and its host tree species. Finally, (d) the invasion of black locust, fostered by its higher habitat suitability as compared to native tree species, may exacerbate the effect of climate change on the lung lichen.

\section{Materials and methods}

\subsection{Studied species and occurrence data}

Lobaria pulmonaria (L.) Hoffm., the lung lichen, is a mainly temperate, holarctic tripartite lichen species with sexual and vegetative dispersal strategies (Scheidegger, 1995), functional differentiation (reproductive and meristematic) of thallus lobes (Scheidegger et al., 1998; Giordani and Brunialti, 2002), large thallus size and thickness that enhances the lichen's water holding capacity (Merinero et al., 2014). Although it is almost at the southern limits of its distribution range, in Italy lung lichen colonizes several native tree substrates along a considerable altitudinal and latitudinal gradient. It is still abundant in humid montane forests of central and southern Italy, reaching the coast in undisturbed areas of Tyrrhenian Italy.

For the purposes of this study, we have selected the trees most frequently colonized by the lung lichen: Quercus ilex, Q. cerris, Q. pubescens, Castanea sativa, and Fagus sylvatica. Additionally, Robinia pseudoacacia (black locust) has been taken into account for describing the possible effects of the most invasive alien tree species across Europe (Vítková et al., 2020). Species occurrence data for tree species were obtained at European scale from Global Biodiversity Information Facility (GBIF, www.gbif.org) and integrated with data from Italian National Forest Inventory (INFC,

2005). Species occurrence data for L. pulmonaria in Europe were obtained from GBIF and integrated from a national database including all available records of Lobaria species in Italy (Nascimbene et al., 2013). Occurrences of each species were spatially filtered and those closer than $1 \mathrm{~km}$ to each other were removed to minimize model overfitting towards environmental biases and overestimation in model performance values. We also performed a temporal filtering of the data in 
order to align them with the climatic data available. In particular, we used occurrences that referred to a time period consistent with that established to define the "current conditions" of the WorldClim bioclimatic variables used in predictive models (1960-1990). Moreover, when this information was available, we also included occurrences reported in literature for periods prior to 1960, but subsequently confirmed by appropriate field inspections. The final dataset had 27,873 occurrences for the lung lichen, 9,775 occurrences for black locust, 4,618 occurrences for Q. cerris, 2,701 occurrences for $Q$. ilex, 3,254 occurrences for $Q$. pubescens, 14,112 occurrences for $C$. sativa and 24,101 occurrences for F. sylvatica. Taking into account the fact that the distribution range of the tree species considered is greater than that observed in Italy, we also used the data of the presence of the species in Europe to include a wider array of the climatic conditions to which the species are subjected. However, the modelled predictions were projected only in Italy where, due to climate change, a strong decline of Lobaria species is expected (Nascimbene et al., 2016). Figures 1 and 2 show the points of presence for tree species and lung lichen in Italy.

\subsection{Climatic variables}

Nineteen bioclimatic variables representative of current (1960-1990) and future (2070) conditions were downloaded from the WorldClim dataset website (version 1.4; http://www.worldclim.org) at 30 arcsec spatial resolution (Hijmans et al., 2005) (about $1 \times 1 \mathrm{~km}$ ). To reduce collinearity and to minimize model overfitting, pairwise Pearson correlation between current bioclimatic predictors was calculated and only six predictors were not highly correlated $(r \leq|0.70|)$. The five variables used in further analyses were: BIO3 — Isothermality, BIO4 - Temperature Seasonality, BIO8 Mean Temperature of Wettest Quarter, BIO 9- Mean Temperature of Driest Quarter, BIO 13 Precipitation of Wettest Month and BIO15 - Precipitation Seasonality. For future conditions, two Representative Concentration Pathways, representing minimum and extreme possible future emission trajectories, were selected: RCP2.6 and RCP8.5. For each RCP we used projections from 
four international recognized circulation models (GCMs), which represent physical processes in the atmosphere, ocean, cryosphere and land surface: CCSM4, HadGEM2-ES, IPSL-CM5A-LR and MPI-ESM-LR.

\subsection{Species distribution modelling}

Species occurrence data and the seven selected variables were used to construct distribution models using the BIOMOD2 package (Thuiller et al., 2009) implemented in R (R Development Core Team, 2019). We applied five SDM techniques: classification tree analysis, CTA (Breiman et al., 1984), generalized linear models, GLM (McCullagh and Nelder, 1989), multivariate adaptive regression splines, MARS (Friedman, 1991), Maxent (Phillips et al., 2006) and random forest, RF (Breiman, 2001). These techniques belong to three different categories of models (i.e. regression methodsMARS and GLM; classification methods-CTA; and machine learning algorithms-RF and Maxent; (Barbet-Massin et al., 2012). For each SDM technique, the number of pseudo-absences was selected according to the recommendation of Barbet-Massin et al. (2012). The predictive performance of the models was evaluated for each pseudoabsence run by repeating a split-sample cross-validation ten times, using a random subset $(70 \%)$ of the initial data set each time to calibrate the models, while the remaining $30 \%$ were used to evaluate the models. The models predicted suitability values between 0 and 1000 at each site. Two different measures for the evaluation of the models were calculated: the area under the curve (AUC) of a receiver operating characteristic (ROC) plot and the true skill statistic (TSS) (Thuiller et al., 2009). For the final ensemble projections, we considered the average among all the models for the same Representative Concentration Pathways.

Taking into consideration the sites that are currently colonized by the lung lichen in Italy, we analyzed the relationships between the climatic suitability of the lichen, that of its native host tree species and that of the black locust, under current conditions and future scenarios. 


\subsection{Spatial analysis}

In order to evaluate the overall distribution of suitable substrate for the lung lichen both in the present and in the future, we first calculated for each grid cell the highest suitability values among them of all native trees (hereafter overall substrate). Furthermore, to evaluate areas where a shift between native and invasive species may occur, we calculated the climatic susceptibility to invasion of each grid cell (hereafter invasibility; Vítková et al., 2020) subtracting the habitat suitability values of invasive species to overall substrate values. As we are only referring to the climatic, thought they are relevant, edaphic and biocoenotic factors involved in the invasibility phenomenon were not taken into account. Positive values suggest that future climate may favour black locust with respect to the native trees while negative ones suggest that future climate may favour the native trees with respect to black locust. Furthermore, we calculated the niche overlap between the lung lichen and both native and invasive trees to test whether climate change may differentially affect the spatial distribution of their climatic niche using the package 'dismo' (Hijmans et al., 2015) implemented in R. The climatic niche overlap was measured by Schoener's D index, which ranges from 0 (no overlap) to 1 (full overlap; Schoener, 1970, Rödder and Engler, 2011).

\section{Results}

Under current climate conditions, all SDM techniques had an excellent performance in modelling all species (Table 1), with AUC values ranging from 0.926 to 0.990 and TSS values ranging from 0.854 to 0.979 (values higher than 0.9 for AUC and values higher than 0.8 for TSS indicate an excellent performance in terms of true positive rates; Araújo et al., 2005), reflecting an appropriate selection of climatic variables.

\subsection{Hypothesis a) Climatic suitability for the lung lichen}


According to the models, the climatic suitability for the lung lichen in Italy under present conditions was highly variable, with very high values (> 900) in vast areas of the eastern Alps, the northern Apennines and in the mountains of southern Italy. In contrast, its climatic suitability was extremely low in most of the lowland areas both in northern and southern Italy (Figure 3). We forecasted a substantial reduction of climatic suitability in both future scenarios (a maximum value of 200 in the RCP26 scenario and a maximum value of 85 in RCP85 scenario; Figure 3B and 3C, respectively).

\subsection{Hypothesis b) Climatic suitability for native host tree species}

According to the models, under present conditions, at least one of the five native trees that usually host the lung lichen had a climatic suitability> 900 in almost all the Italian territory (Figure 4A, Figure S1A-O), except for some areas of the eastern Po Plain. However, these native host tree species are predicted to experience a considerable reduction of their climatic suitability. Both according to RCP26 (Figure 4C) and RCP85 (Figure 4E) circulation models, in 2070 the climatic suitability of these tree species is expected to be $>200$ only in the Alps, and in some areas of the northern and central Apennines.

\subsection{Hypothesis c) Climatic niche overlap between the lung lichen and tree species}

A high to very high niche overlap was found between the lung lichen and tree species (Table 2). In particular, under current conditions, the highest values of niche overlap were detected between the lung lichen and both black locust and F. sylvatica, while in the future the highest values are predicted between the lung lichen and both $Q$. cerris and $C$. sativa (RCP26 scenario) and between the lung lichen and both C. sativa and $Q$. pubescens (RCP85 scenario).

\subsection{Hypothesis d) Climatic suitability for black locust and predicted invasibility}


The current climatic suitability for black locust was very high in large areas of Italy (Figure 4B), with a maximum in the hilly regions of central Italy and the Po Valley. In contrast, its suitability was lower in the driest areas of Mediterranean Italy. The models predicted a decrease in climatic suitability also for black locust (Figure 4D and 4F), but it is expected to be on average high and evenly distributed both along the Italian peninsula and at higher altitudes in northern Italy.

Currently, the lung lichen occurs in areas where its climatic suitability ranged from low to very high and whose invasibility was always quite low (Figure 5A), given that the climatic suitability of its native host tree species in these sites was mostly higher than that of the black locust (i.e. points below grey line in figure 5A). Nevertheless, the highest climatic suitability values of the lung lichen were detected where the invasibility values were relatively high, that is in areas that are roughly equally suitable for its native host tree species and black locust. In contrast, sites with low suitability for the lung lichen occur in areas that are much more suitable for its native host tree species than for black locust (Figure 5A). Under both future scenarios considered in this study, this situation is set to change. In the sites currently colonized, in 2070 the lung lichen is expected to have a very low climatic suitability, and at the same time high invasibility of woods composed of its native host tree species is expected, as indicated by a widespread prevalence of black locust suitability (i.e. points upper the gray line in Figure 5B). However, the few sites that may maintain high suitability for the lung lichen will also be more favorable to its native host tree species. 


\section{Discussion}

In general, our results support the view that climate change may cause range loss of epiphytes by reducing climatic suitability areas (direct effect) and simultaneously decoupling the spatial distribution of its suitable areas from that of areas suitable for its host-tree species (indirect effect). This phenomenon seems to be emphasized by the invasion of alien trees, as in the case of black locust, that may replace native host tree species.

More in details, results support our hypotheses indicating that a reduction of the habitat suitability of the lung lichen across Italy should be expected in the face of climate change and that this is coupled with a co-reduction of the range of its native host tree species (Figure 6). The lung lichen is a sub-oceanic species that in Italy meets its optimal climatic suitability in very humid areas where precipitations or fogs are abundant (Nimis, 2016). In this perspective, temperature warming and increasing aridity that are predicted to occur in the next decades in Mediterranean regions are likely the main climatic factors underpinning its range reduction across Italy (Nascimbene et al., 2016). However, besides direct climate effects, the climate-driven co-reduction of the range of its current host tree species is likely to exacerbate the impact of climate change on this lichen across all its Italian range. This situation seems to be determined by two main processes that act simultaneously: 1) a partial reduction of the spatial overlap between the climatic niche of the lung lichen and that of its host tree species, and 2) the invasion of native woods by black locust (Figure 6).

A potential range decoupling between the lichen and some of its main host tree species is expected, albeit it may be related to contrasting dynamics. According to future scenarios, in the lowland areas, a loss of suitability of both lung lichen and holm oak is expected. On the other hand, holm oak could face an altitude shift, finding higher suitability in the hilly belt, where lung lichen will have low suitability values. The concomitance of these processes will, therefore, be the basis of a considerable climatic niche decoupling between lung lichen and holm oak. As for the overlap between lung lichen and beech, both species will undergo a substantial reduction of suitability at 
lower altitudes, while both will resist in the eastern Alps. However, unlike the beech, lung lichen will lose suitability in all non-alpine beech forests (except for some areas of the central Apennines). In summary, most of the predicted decoupling niche processes will occur because lung lichen will undergo a more significant reduction in its suitability compared to its tree substrates. The maintenance of climatic niche overlap between the lung lichen and its preferred substrates in the central part of the gradient is probably due to the fact that this is a more buffered situation in which the lichen can track at least one of its preferred substrates.

Black locust was mainly introduced in Italy as ornamental or for landscaping and erosion control (Benesperi et al., 2012; Nascimbene et al., 2015) and recently it was recognized as invasive alien species of major importance. Currently, in Italy its spread is enhanced by urbanization in hilly areas, intensive forest management in native forests and abandonment of agricultural areas (Campagnaro et al., 2018; Sitzia et al., 2018) and its eradication is almost impossible, while only mitigation of its impact could be handled. The invasion of black locust at the expenses of native trees could deplete the most suitable substrates in areas that are expected to be climatically suitable for the lung lichen. Thus, the spread of black locust that is interactively enhanced by climate change and human disturbance (Kleinbauer et al., 2010; Thurm et al., 2018) would further reduce the range of the lung lichen across Italy. This mechanism is expected to mainly act at the intermediate part of the environmental gradient of the lung lichen, i.e. in Quercus pubescens, Q. cerris, and Castanea sativa forests that are the forest types more prone to black locust invasion (Vítková et al., 2020). However, the few sites that will maintain high suitability for the lung lichen are also expected to be more favorable to its native host tree species, thus providing refugia that can mitigate the impact of black locust invasion. Moreover, the lung lichen may adapt to a range of supplementary substrates as most probably happened in the past in the Apennines, when semi-natural oak and beech forests were much more exploited and extensively managed chestnut orchards strongly expanded their range due to increasing economic value (Conedera et al., 2004), providing a suitable secondary 
habitat for the lung lichen (Matteucci et al., 2012). However, besides the potential of black locust bark to provide a suitable substrate to the lung lichen, black locust formations are unlikely suitable for this species due to their intensive management based on very short rotation cycles (Radke et al., 2013; Straker et al., 2015). This view is supported by results of previous studies indicating strong compositional differences between lichen communities of native tree forests and secondary black locust formations that mainly host ruderal species (Nascimbene et al., 2010). Regardless of the physico-chemical characteristics of its bark, the potential of black locust to host the lung lichen is hampered by the fact that black locust formations are intensively managed according with short rotation coppice cycles. It should be tested if adaptive management could be applied to black locust formations in order to mitigate the effects of climate change on forest epiphytes. This information would help to refine predictive models, also accounting for potential adaptation dynamics and microrefugia (Ellis, 2020) that allow the persistence of the species under unsuitable climatic conditions. In contrast to vascular plant modelling, adaptation dynamics are still poorly accounted for lichens (Ellis, 2019), thus requiring further research.

Currently, other major invasive tree species potentially competing with the common hosts of the lung lichen occur only in coastal and lowland ranges, as in the case of Acacia spp. and Ailanthus altissima (Mill.) Swingle, whose negative effects on native vascular plant communities are already well documented (e.g. Lazzaro et al., 2014). Information about their role as potential hosts for epiphytic lichens are still scanty in Italy, but our preliminary field investigations indicate that also these tree species would negatively affect different facets of biodiversity, as in the case of black locust (Lazzaro et al., 2018).

\section{Conclusions}

The case of lung lichen and black locust in Italy highlights that epiphytes are prone to both direct and indirect effects of climate change and that the invasion of alien trees may have consequences 
that are still poorly evaluated for epiphytes. However, we are aware that our results, based on the comparison of climatic suitability patterns between the lung lichen, its main host tree species and black locust, may fail to exhaustively analyze this complex system. For example, direct experimental testing (i.e. with lichen transplants) would be required to elucidate the potential of black locust to provide secondary habitat to the lung lichen under different climatic and management conditions. Also, more accurate historical reconstructions may help to elucidate past dynamics that inform on future trajectories (Fritz et al., 2008; Marmor et al., 2011) and a broad scale (e.g. at the European level) evaluation of the substrate preference of epiphytic lichens would strongly help to better model their distribution under climate change scenarios. Finally, these dynamics could be better embedded in a complex context in which also the effects of air pollution (Cristofolini et al., 2008; Giordani et al., 2014) and forest management (Giordani, 2012) are evaluated. This would likely provide e more exhaustive and even more dramatic picture of the risks that are threatening epiphytic lichens across Europe. 


\section{References}

Araújo, M.B., Pearson, R.G., Thuiller, W., Erhard, M. (2005) Validation of species-climate impact models under climate change. Global Change Biology, 11 (9): 1504-1513.

Barbet-Massin, M., Jiguet, F., Albert, C. H., \& Thuiller, W. (2012) Selecting pseudo-absences for species distribution models: how, where and how many? Methods in Ecology and Evolution, 3(2): 327-338.

Bellard C., Bertelsmeier C., Leadley P., Thuiller W., Courchamp F. (2012) Impacts of climate change on the future of biodiversity. Ecology Letters, 365-377: 365-377.

Benesperi R., Nascimbene J., Lazzaro L., Bianchi E., Tepsich A., Longinotti S., Giordani P. (2018). Successful conservation of the endangered forest lichen Lobaria pulmonaria requires knowledge of fine-scale population structure. Fungal Ecology, 33: 65-71.

Breiman, L. (2001) Random Forests. Machine Learning, 45(1): 5-32.

Breiman, L., Friedman, J., Stone, C. J., Olshen, R. A. (1984) Classification and Regression Trees. Wadsworth International Group, Belmont, California.

Campagnaro, T., Nascimbene, J., Tasinazzo, S., Trentanovi, G., Sitzia, T., 2018. Exploring patterns, drivers and structure of plant community composition in alien Robinia pseudoacacia secondary woodlands. iForest - Biogeosciences and Forestry 11, 586. https://doi.org/10.3832/ifor2687-011

Casazza, G., Giordani, P., Benesperi, R., Foggi, B., Viciani, D., Filigheddu, R., Farris, E., Bagella, S., Pisanu, S., Mariotti, M.G. (2014) Climate change hastens the urgency of conservation for range-restricted plant species in the central-northern Mediterranean region. Biological Conservation, 179: 129-138.

Conedera, M., Krebs, P., Tinner, W., Pradella, M., Torriani, D. (2004) The cultivation of Castanea sativa (Mill.) in Europe. From its origin to its diffusion on a continental scale. Vegetation History and Archaeobotany, 13(3): 161-179. 
Cristofolini, F., Giordani, P., Gottardini, E., Modenesi, P., 2008. The response of epiphytic lichens to air pollution and subsets of ecological predictors: A case study from the Italian Prealps. Environmental Pollution 151, 308-317.

Dyderski, M.K., Paź, S., Frelich, L.E., Jagodziński, A.M. (2018) How much does climate change threaten European forest tree species distributions? Global Change Biology, 24:1150-1163.

Ellis, C.J. (2019) Climate change, bioclimatic models and the risk to lichen diversity. Diversity, 11, 54.

Ellis, C.J. (2020) Microclimatic refugia in riparian woodland: A climate change adaptation strategy. Forest Ecology and Management, 462, 118006.

Friedman, J. H. (1991) Multivariate Adaptive Regression Splines. The Annals of Statistics, 19(1): $1-67$.

Fritz, O., Gustafsson, L., Larsson, K. (2008) Does forest continuity matter in conservation? - A study of epiphytic lichens and bryophytes in beech forests of southern Sweden. Biological Conservation, 141: 655-668.

Fritz, O., Brunet, J., Caldiz, M. (2009) Interacting effects of tree charactersictics on the occurrence of rare epiphytes in a Swedish boreal forest. The Bryologist, 112: 488-505.

Gauslaa, Y. (2014) Rain, dew, and humid air as drivers of morphology, function and spatiald distribution in epiphytic lichens. Lichenologist, 46 (1): 1-16.

Gauslaa, Y., Lie, M., Solhaug, K.A., Ohlson, M. (2006). Growth and ecophysiological acclimation of the foliose lichen Lobaria pulmonaria in forests with contrasting light climates. Oecologia, 147 (3): 406-416.

Giordani, P., 2012. Assessing the effects of forest management on epiphytic lichens in coppiced forests using different indicators. Plant Biosystems - An International Journal Dealing with all Aspects of Plant Biology 1-10. https://doi.org/10.1080/11263504.2011.654136 
Giordani, P., Brunialti, G., Bacaro, G., Nascimbene, J. (2012) Functional traits of epiphytic lichens as potential indicators of environmental conditions in forest ecosystems. Ecological Indicators, 18: 413-420.

Giordani, P., Calatayud, V., Stofer, S., Seidling, W., Granke, O., Fischer, R., 2014. Detecting the nitrogen critical loads on European forests by means of epiphytic lichens. A signal-to-noise evaluation. Forest Ecology and Management 311, 29-40. https://doi.org/10.1016/j.foreco.2013.05.048

Giordani, P., Brunialti, G. (2002) Anatomical and histochemical differentiation in lobes of the lichen Lobaria pulmonaria. Mycological Progress 1: 131-136.

Hijmans, R. J., Cameron, S. E., Parra, J. L., Jones, P. G., Jarvis, A. (2005) Very high resolution interpolated climate surfaces for global land areas. International Journal of Climatology, 25(15): 1965-1978.

Hijmans, R. J., Phillips, S., Leathwick, J., Elith, J. (2015) dismo: Species distribution modelling. https://CRAN.R-project.org/package=dismo

HilleRisLambers, J., Harsch, M. A., Ettinger, A. K., Ford, K. R., Theobald, E. J. (2013) How will biotic interactions influence climate change - induced range shifts? Annals of the New York Academy of Sciences, 1297: 112-125.

Kleinbauer, I., Dullinger, S., Peterseil, J., Essl, F. (2010) Climate change might drive the invasive tree Robinia pseudoacacia into nature reserves and endangered habitats. Biological Conservation, 143: $382-390$.

Kuhn, E., Gégout, J.C. (2019) Highlighting declines of cold-demanding plant species in lowlands under climate warming. Ecography, 42(1): 36-44.

Jüriado, I., Liira, J., Paal, J., Suija A. (2009) Tree and stand level variables influencing diversity of lichens on temperate broad-leaved trees in boreo-nemoral floodplain forests. Biodiversity and Conservation, 18: 105-125. 
INFC (2005) Inventario Nazionale delle Foreste e dei Serbatoi Forestali di Carbonio. Ministero delle Politiche Agricole Alimentari e Forestali, Ispettorato Generale - Corpo Forestale dello Stato. Consiglio per la Ricerca e Sperimentazione in Agricoltura Unità di ricerca per il Monitoraggio e la Pianificazione Forestale (CRA - MPF).

Insarov, G., Schroeter, B. (2002) Lichen monitoring and climate change. In: Monitoring with Lichens, Monitoring Lichens; Nimis, P.L., Scheidegger, C., Wolseley, P., Eds.; Kluwer Academic Publishers: Dordrecht, The Netherlands, pp. 183-201.

Lazzaro, L., Giuliani, C., Fabiani, A., Agnelli, A.E., Pastorelli, R., Lagomarsino, A., Benesperi, R., Calamassi, R., Foggi, B., 2014. Soil and plant changing after invasion: The case of Acacia dealbata in a Mediterranean ecosystem. Science of The Total Environment 497-498, 491498. https://doi.org/10.1016/j.scitotenv.2014.08.014

Lazzaro, L., Mazza, G., d'Errico, G., Fabiani, A., Giuliani, C., Inghilesi, A.F., Lagomarsino, A., Landi, S., Lastrucci, L., Pastorelli, R., Roversi, P.F., Torrini, G., Tricarico, E., Foggi, B., 2018. How ecosystems change following invasion by Robinia pseudoacacia: Insights from soil chemical properties and soil microbial, nematode, microarthropod and plant communities. Science of The Total Environment 622-623, 1509-1518. https://doi.org/10.1016/j.scitotenv.2017.10.017

Lewis, J.E.J., Ellis, C.J. (2010) Taxon-compared with trait-based analysis of epiphytes, and the role of tree species and tree age in community composition Plant Ecology and Diversity, 3: 203210.

Marini, L., Nascimbene, J., Nimis, P.L. (2011) Large-scale patterns of epiphytic lichen species richness: photobiont-dependent response to climate and forest structure. Science of the Total Environment, 409: 4381-4386.

Marmor, L., Tõrra, T., Saag, L., Randlane, T. (2011) Effects of forest continuity and tree age on epiphytic lichen biota in coniferous forests in Estonia. Ecological Indicators, 11: 1270-1276. 
Matteucci, E., Benesperi, R., Giordani, P., Piervittori, R., Isocrono, D. (2012). Epiphytic lichen communities in chestnut stands in central-North Italy. Biology, 67: 61-70.

McCullagh, P., Nelder, J.A. (1989) Generalized Linear Models. Taylor \& Francis Ltd.

McDonald, L., Van Woundenberg, M., Dorin, B., Adcock, A.M., McMullin, R.T., Cottenie, K. (2017) The effects of bark quality on corticolous lichen community composition in urban parks of southern Ontario. Botany 95(12): 1141-1149.

Merinero, S., Rubio-Salcedo, M., Aragón, G., Martínez, I. (2014) Environmental factors that drive the distribution and abundance of a threatened cyanolichen in Southern Europe: A multiscale approach. American Journal of Botany, 101 (11): 1876-1885.

Nadal-Sala, D., Hartig, F., Carlos A.Gracia, C.A., Sabaté, S. (2019) Global warming likely to enhance black locust (Robinia pseudoacacia L.) growth in a Mediterranean riparian forest. Forest Ecology and Management, 449 (2019) 117448.

Nascimbene, J., Marini, L., Nimis., P.L. (2009) Influence of tree species on epiphytic macrolichens in temperate mixed forests of northern Italy. Canadian Journal of Forest Research, 39: 785791.

Nascimbene, J., Benesperi, R., Brunialti, G., Catalano, I., Vedove, M. D., Grillo, M., Isocrono, D., Matteucci, E., Potenza, G., Puntillo, D., Puntillo, M., Ravera, S., Rizzi, G., Giordani, P. (2013). Patterns and drivers of $\beta$-diversity and similarity of Lobaria pulmonaria communities in Italian forests. Journal of Ecology, 101(2): 493-505.

Nascimbene, J., Casazza, G., Benesperi, R., Catalano, I., Cataldo, D., Grillo, M., Isocrono, D., Matteucci, E., Ongaro, S., Potenza, G., Puntillo, D., Ravera, S., Zedda, L., Giordani, P. (2016) Climate change fosters the decline of epiphytic Lobaria species in Italy. Biological Conservation, 201: 377-384. 
Nascimbene, J., Lazzaro, L., Benesperi, R. (2015) Patterns of $\beta$-diversity and similarity reveal biotic homogenization of epiphytic lichen communities associated with the spread of black locust forests. Fungal Ecology, 14:1-7.

Nascimbene, J., Marini L. (2010) Oak forest exploitation and black locust invasion caused severe shifts in epiphytic lichen communities in northern Italy. Science of the Total Environment, 408: 5506-5512.

Nascimbene, J., Nimis, P.L., Benesperi, R. (2012) Mature non-native black-locust (Robinia pseudoacacia L.) forest does not regain the lichen diversity of the natural forest. Science of the Total Environment, 421-422: 197-202.

Nascimbene, J., Benesperi, R., Giordani, P., Grube, M., Marini, L., Vallese, C., Mayrhofer, H. (2019) Could hair-lichens of high-elevation forests help detect the impact of global change in the Alps? Diversity, 2019, 11, 45.

Nimis P. L. (2016) The lichens of Italy. A second annotated catalogue. EUT Edizioni Università di Trieste, Trieste. 739 pp.

Otálora, M.A., Belinchón, R., Prieto, M., Aragón, G., Izquierdo, P., Martínez, I. (2015) The threatened epiphytic lichen Lobaria pulmonaria in the Iberian Peninsula: genetic diversity and structure across a latitudinal gradient. Fungal Biology, 119 (9): 802-811.

Paoli, L., Benesperi, R., Fačkovcova, Z., Nascimbene, J., Ravera, S., Marchetti, M., Anselmi, B., Landi, M., Landi, S., Bianchi, E., Di Nuzzo, L., Lackovičova, A., Vannini, A., Loppi, S., Guttova, A. (2019) Impact of forest management on threatened epiphytic macrolichens: evidence from a Mediterranean mixed oak forest (Italy). iForest - Biogeosciences and Forestry, 12: 383-388.

Parmesan, C., Yohe, G. (2003) A globally coherent fingerprint of climate change impacts across natural systems. Nature, 421:37-42. 
Phillips, S. J., Anderson, R. P., Schapire, R. E. (2006) Maximum entropy modeling of species geographic distributions. Ecological Modelling, 190(3-4): 231-259.

Radtke, A., Ambraß, S., Zerbe, S., Tonon, G., Fontana, V., Ammer, C. (2013) Traditional coppice forest management drives the invasion of Ailanthus altissima and Robinia pseudoacacia into deciduous forests. Forest Ecology and Management, 291: 308-31.

Richardson, D.M., Rejmánek, M. (2011) Trees and shrubs as invasive species-a global review. Diversity and Distributions, 7:788-809.

R Core Team (2019) R: A language and environment for statistical computing. R Foundation for Statistical Computing, Vienna, Austria. URL https://www.r-project.org/.

Rödder, D., Engler, J.O. (2011) Quantitative metrics of overlaps in Grinnellian niches: advances and possible drawbacks. Global Ecology and Biogeography 20: 915-927.

Rubio-Salcedo, M., Merinero, S., Martínez, I. (2015) Tree species and microhabitat influence the population structure of the epiphytic lichen Lobaria pulmonaria. Fungal Ecology, 18: 1-9. Scheidegger, C. (1995) Early development of transplanted isidioid soredia of Lobaria pulmonaria in an endangered population. The Lichenologist, 27: 361-374.

Scheidegger, C., Frey, B., Walser, J.-C. (1998) Reintroduction and augmentation of populations of the endangered Lobaria pulmonaria: Methods and concepts. Lobarion lichens as indicators of primeval forests of Eastern Carpathians (Darwin International Workshop) 33-52.

Schoener, T.W. (1970) Nonsynchronous Spatial Overlap of Lizards in Patchy Habitats. Ecology, 51: 408-418.

Schroeter, B., Kappen, L., Schulz, F., Sancho, L.G. (2000). Seasonal variation in the carbon balance of lichens in the maritime Antarctic: Long-term measurements of photosynthetic activity in Usnea aurantiaco-atra. In: Antarctic Ecosystems: Models for Wider Ecological Understanding; Davison, W., Howard-Williams, C., Broady, P., Eds.; Caxton Press: Christchurch, New Zealand, pp. 258-262. 
Sitzia, T., Campagnaro, T., Kotze, D.J., Nardi, S., Ertani, A., 2018. The invasion of abandoned fields by a major alien tree filters understory plant traits in novel forest ecosystems. Sci Rep 8, 1-10. https://doi.org/10.1038/s41598-018-26493-3

Straker, K.C., Quinn, L.D., Voigt, T.B., Lee, D.K., Kling, G.J. (2015) Black locust as a bioenergy feedstock: a review. BioEnergy Research, 8: 1117-1135.

Thomas, C.D., Cameron, A., Green, R.E., Bakkenes, M., Beaumont, L.J., Collingham, Y.C., Erasmus, B.F.N., De Siqueira, M.F., Grainger, A., Hannah, L., Hughes, L., Huntley, B., Van Jaarsveld, A.S., Midgley, G.F., Miles, L., Ortega-Huerta, M.A., Peterson, A.T., Phillips, O.L., Williams, S.E. (2004) Extinction risk from climate change. Nature 427:145-148. Thuiller, W., Lafourcade, B., Engler, R., \& Araújo, M. B. (2009) BIOMOD - A Platform for Ensemble Forecasting of Species Distributions. Ecography, 32(3): 369-373.

Thurm, E.A., Hernandez, L., Baltensweiler, A., Ayan, S., Rasztovits, E., Bielak, K., Zlatanov, T.M., Hladnik, D., Balic, B., Freudenschuss, A., Büchsenmeister, R., Falk, W. (2018) Alternative tree species under climate warming in managed European forests. Forest Ecology and Management, 430: 485-497.

Van der Putten, W. H., M. Macel, Visser, M. E. (2010) Predicting species distribution and abundance responses to climate change: why it is essential to include biotic interactions across trophic levels. Philosophical Transactions of the Royal Society B: Biological Sciences, 365: 2025-2034.

van Stan II, .J.T., Pypker T.G. (2015) A review and evaluation of forest canopy epiphyte roles in the partitioning and chemical alteration of precipitation Science of the Total Environment, 536: 813-824.

Vítková, M., Müllerová, J., Sádlo, J., Pergl, J., Pyšek, P. (2017) Black locust (Robinia pseudoacacia) beloved and despised: a story of an invasive tree in Central Europe. Forest Ecology and Management, 384: 287-302. 
Vítková, M., Sádlo, J., Roleček, J., Petřík, P., Sitzia, T., Müllerová, J., Pyšek, P. (2020) Robinia pseudoacacia-dominated vegetation types of Southern Europe: Species composition, history, distribution and management. Science of the Total Environment 707: 134857.

Widmer, I., Dal Grande, F., Excoffier, L., Holderegger, R., Keller, C., Mikryukov, V.S., Scheidegger, C. (2012) European phylogeography of the epiphytic lichen fungus Lobaria pulmonaria and its green algal symbiont. Molecular Ecology, 21 (23): 5827-5844.

Zedda, L., Rambold, G. (2015) The diversity of lichenised fungi: ecosystem functions and ecosystem services. D.K. Upreti, P.K. Divakar, V. Shukla, R. Bajpai (Eds.), Recent Adv. Lichenol., New Delhi, pp. 121-145. 


\section{Tables}

Table 1. Evaluation of individual modelling techniques for studied species. Statistics given are the mean values and the associated standard deviations (in brackets) for area under the curve (AUC), the true skill statistic (TSS) and Kappa statistic (KAPPA). Accuracy classification for AUC (1>excellent>0.9>good $>0.8>$ fair $>0.7>$ poor $>0.6>$ fail $)$ and for TSS/KAPPA (1> excellent $>0.8>$ good $>0.6>$ fair $>0.4>$ poor $>0.2>$ fail) following Swets' scale modified by Araújo et al. 2005. CTA, Classification Tree Analysis; GLM, Generalized Linear Models; MARS Multiple Additive Regression Spline; MAX, Maximum Entropy; RF, Random Forest.

\begin{tabular}{|c|c|c|c|c|c|c|}
\hline Species & Evaluation model & \multicolumn{5}{|c|}{ Algorithm } \\
\hline \multirow{7}{*}{ L. pulmonaria } & \multirow{3}{*}{ AUC } & CTA & GLM & MARS & MAX & $\mathbf{R F}$ \\
\hline & & 0.969 & 0.979 & 0.988 & 0.949 & 0.992 \\
\hline & & $(0.008)$ & $(0.006)$ & (0.004) & $(0.018)$ & $(0.003)$ \\
\hline & & 0.703 & 0.825 & 0.818 & 0.404 & 0.926 \\
\hline & KAPPA & $(0.055)$ & $(0.019)$ & $(0.026)$ & $(0.115)$ & $(0.011)$ \\
\hline & & 0.933 & 0.929 & 0.940 & 0.886 & 0.965 \\
\hline & & $(0.012)$ & $(0.012)$ & $(0.01)$ & $(0.033)$ & $(0.007)$ \\
\hline \multirow{6}{*}{ R. pseudoacacia } & & 0.967 & 0.989 & 0.991 & 0.927 & 0.995 \\
\hline & AUC & $(0.011)$ & $(0.003)$ & $(0.002)$ & $(0.015)$ & $(0.002)$ \\
\hline & & 0.760 & 0.824 & 0.829 & 0.445 & 0.929 \\
\hline & KAPPA & $(0.038)$ & $(0.016)$ & $(0.016)$ & $(0.071)$ & $(0.014)$ \\
\hline & & 0.919 & 0.922 & 0.924 & 0.854 & 0.951 \\
\hline & & $(0.012)$ & $(0.011)$ & $(0.011)$ & $(0.026)$ & $(0.010)$ \\
\hline \multirow{6}{*}{ Q. ilex } & & 0.983 & 0.996 & 0.997 & 0.973 & 0.997 \\
\hline & AUC & $(0.006)$ & $(0.002)$ & $(0.001)$ & $(0.007)$ & $(0.002)$ \\
\hline & & 0.958 & 0.979 & 0.974 & 0.919 & 0.982 \\
\hline & KAPPA & $(0.013)$ & $(0.008)$ & $(0.009)$ & $(0.026)$ & $(0.007)$ \\
\hline & & 0.96 & 0.974 & 0.972 & 0.935 & 0.979 \\
\hline & & $(0.012)$ & $(0.009)$ & $(0.009)$ & $(0.019)$ & $(0.008)$ \\
\hline \multirow{2}{*}{$Q \cdot$ pubescens } & & 0.979 & 0.994 & 0.994 & 0.944 & 0.996 \\
\hline & AUC & $(0.006)$ & $(0.003)$ & (0.003) & $(0.010)$ & $(0.002)$ \\
\hline
\end{tabular}




\begin{tabular}{|c|c|c|c|c|c|c|}
\hline & & 0.949 & 0.966 & 0.964 & 0.824 & 0.970 \\
\hline & KAPPA & $(0.012)$ & $(0.008)$ & (0.007) & $(0.038)$ & $(0.007)$ \\
\hline & & 0.949 & 0.96 & 0.958 & 0.883 & 0.969 \\
\hline & & (0.009) & (0.009) & $(0.01)$ & $(0.020)$ & $(0.007)$ \\
\hline \multirow{6}{*}{ C. sativa } & & 0.977 & 0.994 & 0.994 & 0.951 & 0.994 \\
\hline & ก & (0.008) & $(0.003)$ & (0.003) & $(0.014)$ & $(0.003)$ \\
\hline & & 0.853 & 0.949 & 0.945 & 0.516 & 0.969 \\
\hline & KAPPA & $(0.04)$ & $(0.012)$ & (0.013) & $(0.116)$ & $(0.005)$ \\
\hline & & 0.95 & 0.962 & 0.961 & 0.894 & 0.973 \\
\hline & 1ND & $(0.011)$ & $(0.01)$ & $(0.011)$ & (0.024) & $(0.007)$ \\
\hline \multirow{6}{*}{ Q. cerris } & & 0.983 & 0.995 & 0.995 & 0.965 & 0.996 \\
\hline & 18 & (0.006) & $(0.003)$ & $(0.003)$ & $(0.008)$ & $(0.002)$ \\
\hline & & 0.939 & 0.969 & 0.966 & 0.871 & 0.975 \\
\hline & KAPPA & (0.014) & (0.009) & (0.008) & (0.026) & $(0.007)$ \\
\hline & & 0.959 & 0.970 & 0.965 & 0.926 & 0.975 \\
\hline & IDS & $(0.008)$ & $(0.011)$ & $(0.01)$ & $(0.015)$ & $(0.010)$ \\
\hline \multirow{6}{*}{ F. sylvatica } & & 0.977 & 0.990 & 0.989 & 0.945 & 0.991 \\
\hline & & $(0.008)$ & $(0.004)$ & $(0.005)$ & $(0.017)$ & (0.004) \\
\hline & & 0.809 & 0.952 & 0.957 & 0.366 & 0.967 \\
\hline & KAPPA & (0.047) & (0.009) & $(0.01)$ & $(0.126)$ & (0.008) \\
\hline & & 0.951 & 0.961 & 0.958 & 0.883 & 0.973 \\
\hline & TSS & $(0.012)$ & (0.009) & $(0.010)$ & $(0.033)$ & $(0.008)$ \\
\hline
\end{tabular}


Table 2. Results of niche overlap among the lung lichen (Lobaria pulmonaria), its potential substrates and the invasive species black locust (Robinia pseudoacacia).

\begin{tabular}{lccc}
\hline & \multicolumn{3}{c}{ Lung lichen } \\
\hline & Present & RCP26 & RCP85 \\
\hline Quercus ilex & 0.718 & 0.687 & 0.616 \\
\hline Quercus pubescens & 0.771 & 0.756 & 0.723 \\
\hline Castanea sativa & 0.791 & 0.793 & 0.751 \\
\hline Quercus cerris & 0.767 & 0.803 & 0.720 \\
\hline Fagus sylvatica & 0.804 & 0.721 & 0.682 \\
\hline Overall native trees & $\mathbf{0 . 7 8 4}$ & $\mathbf{0 . 8 3 3}$ & $\mathbf{0 . 7 8 3}$ \\
\hline Black locust & & & \\
\hline
\end{tabular}




\section{Figure captions}

Figure 1. Distribution of the lung lichen (Lobaria pulmonaria) on five main native tree substrates in Italy. Location when the lichen occurs on other tree substrates are also reported (e.g., Acer spp., Alnus spp., Carpinus betulus, Fraxinus spp., Abies alba, Quercus petraea, Ostrya carpinifolia, Larix decidua). 


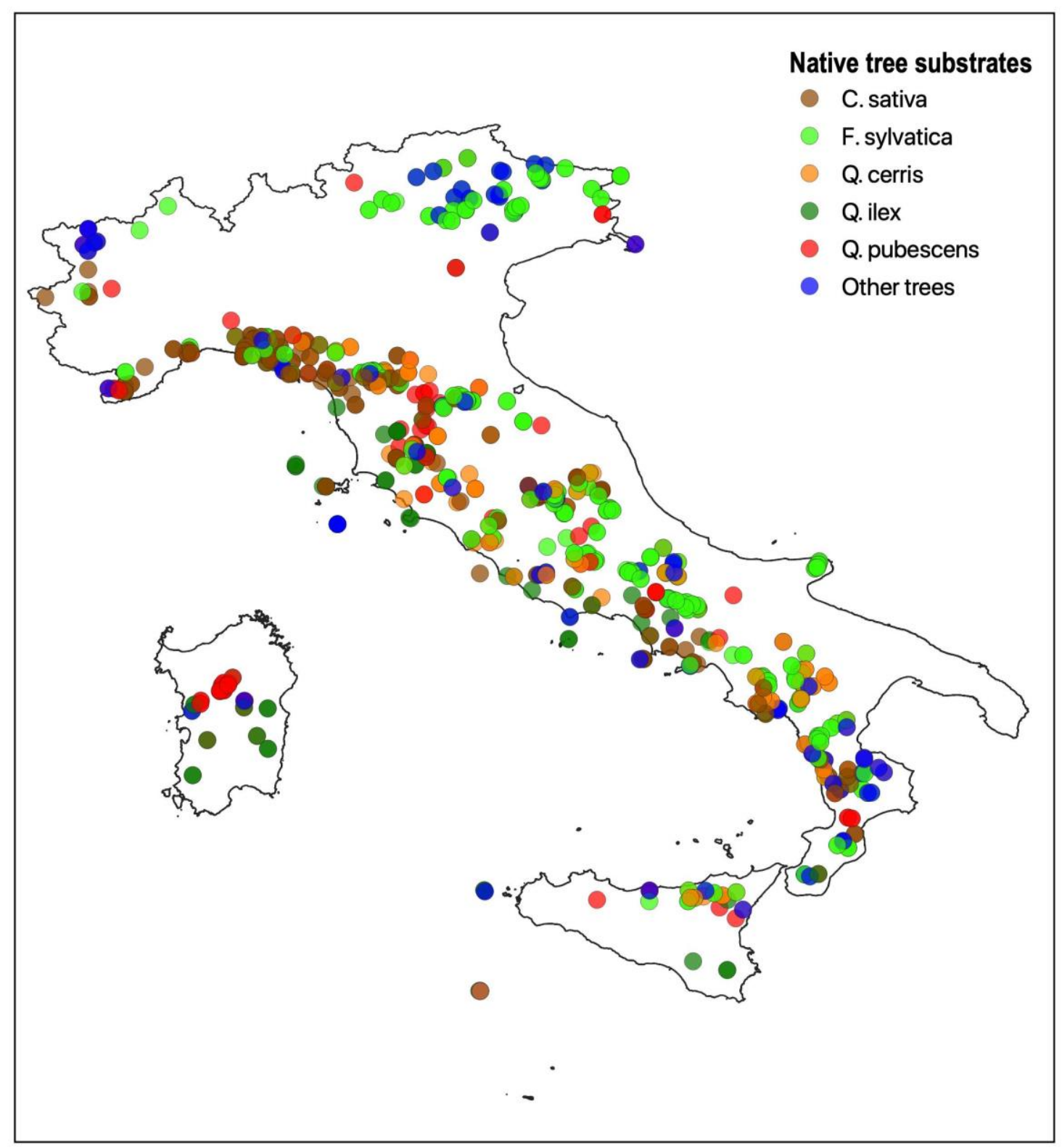


Figure 2. Distribution of black locust (Robinia pseudoacacia) and of the native tree species that usually host the lung lichen in Italy.
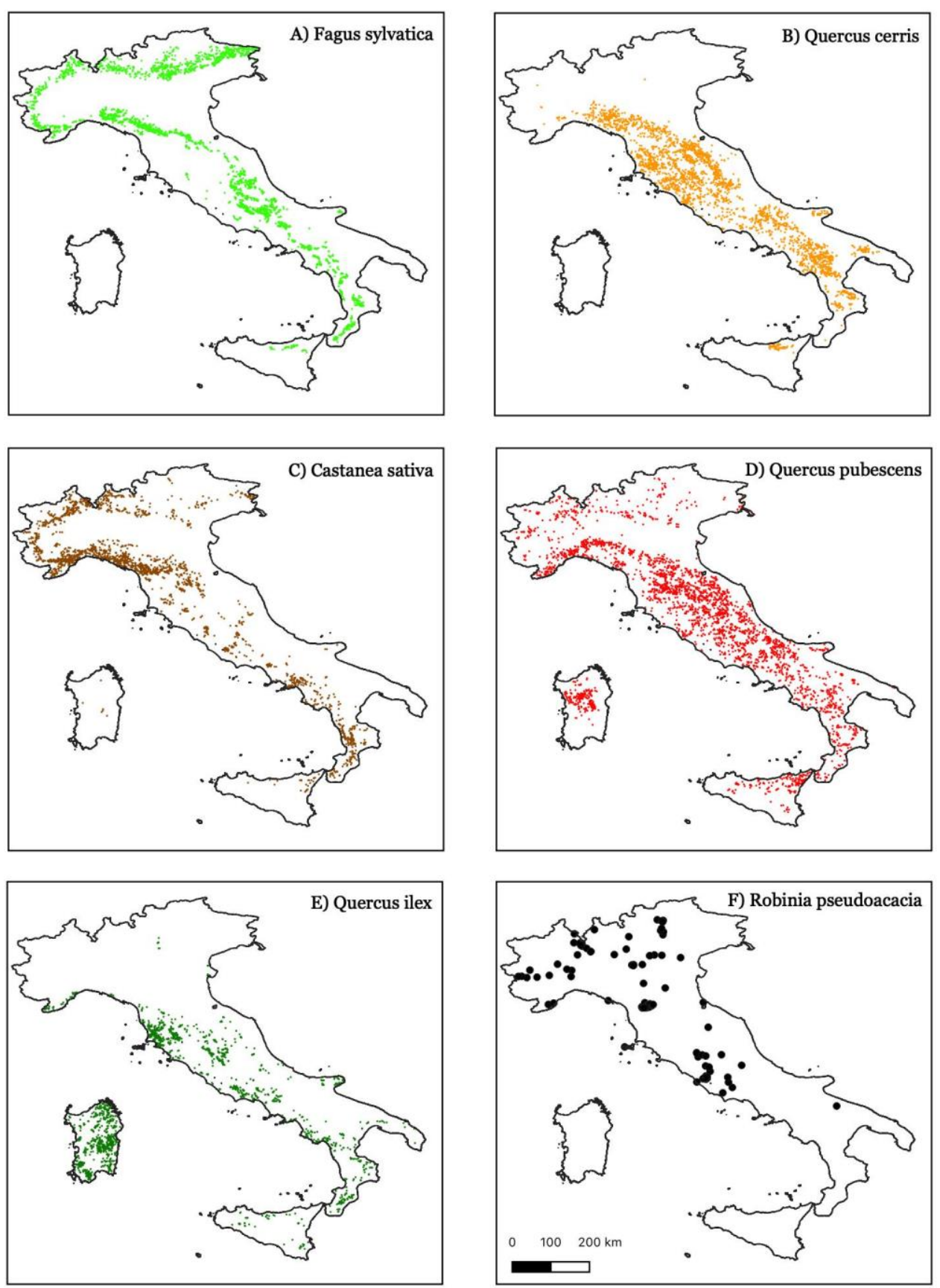
Figure 3. Habitat suitability of the lung lichen in Italy under current conditions (A), RCP26 (B) and RCP85 circulation models (C).
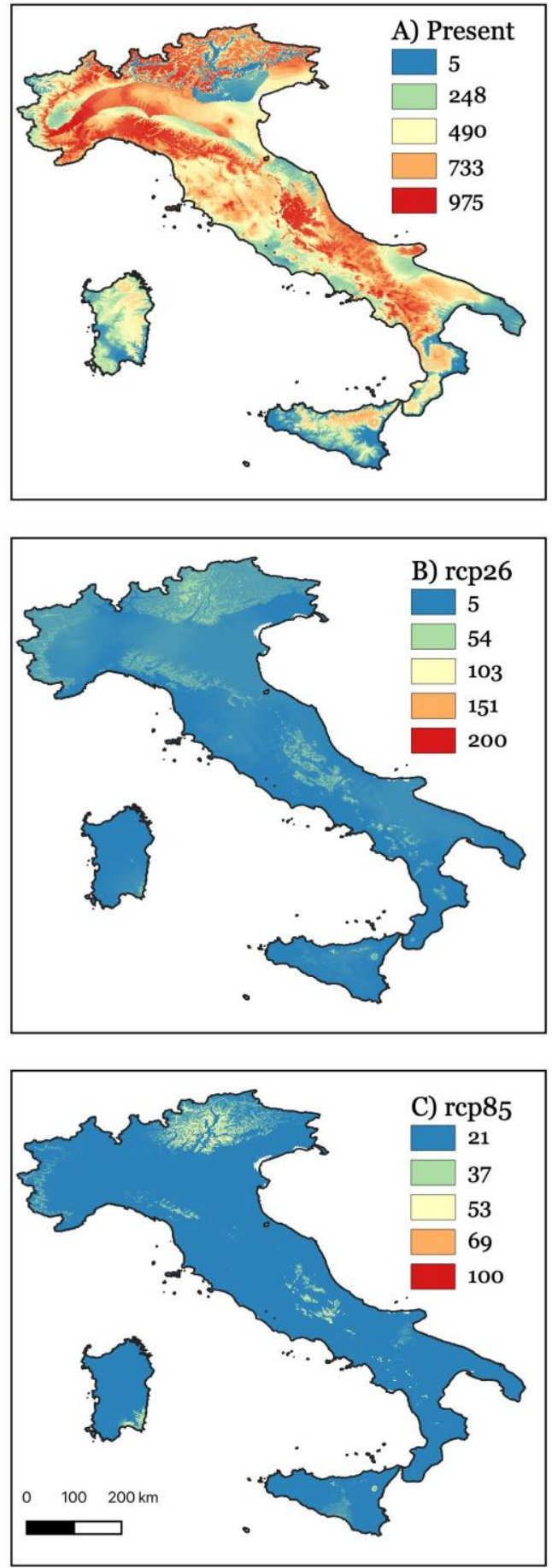
Figure 4. Habitat suitability of the native tree species (maximum value among the five potential substrates) that usually host the lung lichen in Italy $(\mathrm{A}, \mathrm{C}, \mathrm{E})$ and of black locust $(\mathrm{B}, \mathrm{D}, \mathrm{F})$ under current conditions (A, B), RCP26 (C, D) and RCP85 circulation models (E, F).
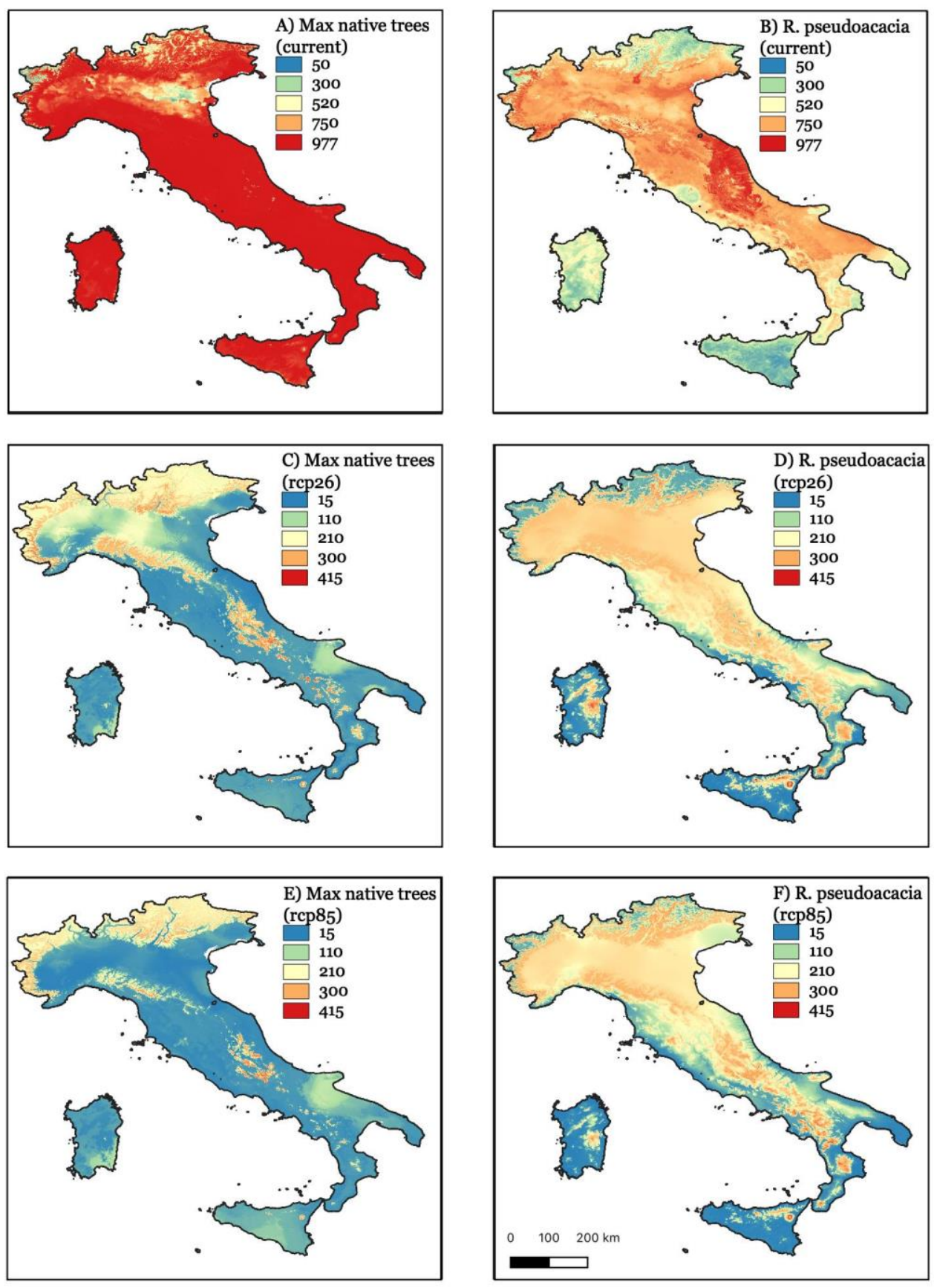
Figure 5. Relationship between the habitat suitability of the lung lichen and that of the tree species under current climatic conditions (A), and according to RCP26 and RCP85 future scenarios (B) in sites currently colonized by the lung lichen in Italy (circles: current conditions, crosses: RCP26, triangles: RCP85). In the figures, axis y has positive values when the habitat suitability of black locust > habitat suitability of native host tree species and negative values in the opposite case. Lines represent fitting lines according to linear models (dotted line: current conditions, solid line: RCP26, dashed line: RCP85); gray ribbons are confidence intervals at $95 \%$.
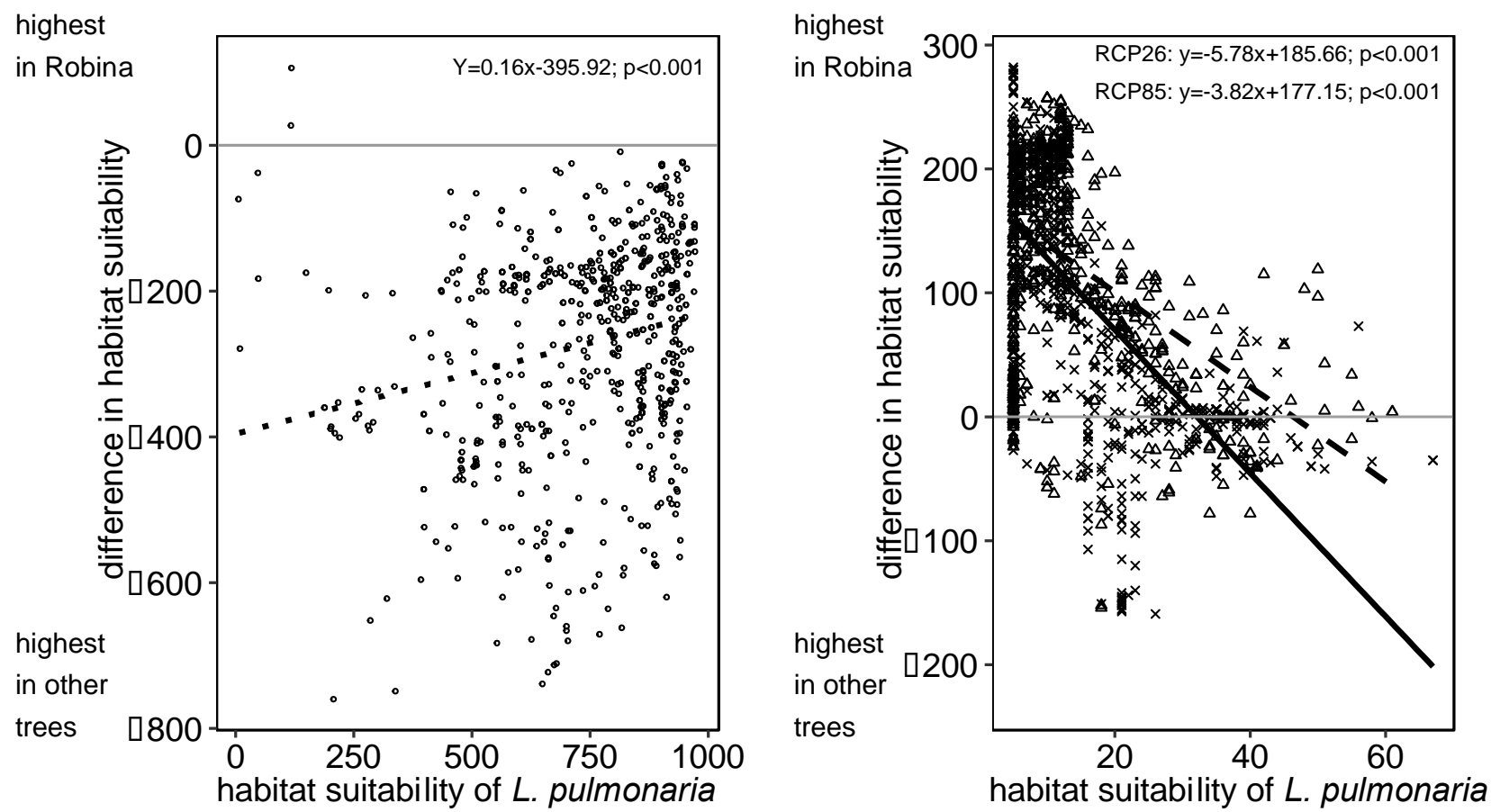
Figure 6. Summary of the main results for future scenarios in different altitudinal belt in Italy following the four proposed hypotheses ( $\mathrm{Hp}$ in the figure). Hypothesis a): reduction of the habitat suitability of the lung lichen across Italy due to climate change; hypothesis b): reduction of the range of its native host tree species; hypothesis c): reduction of the climatic niche overlap between the epiphyte and its host tree species; hypothesis d): invasion of black locust, fostered by its higher habitat suitability as compared to native tree species.

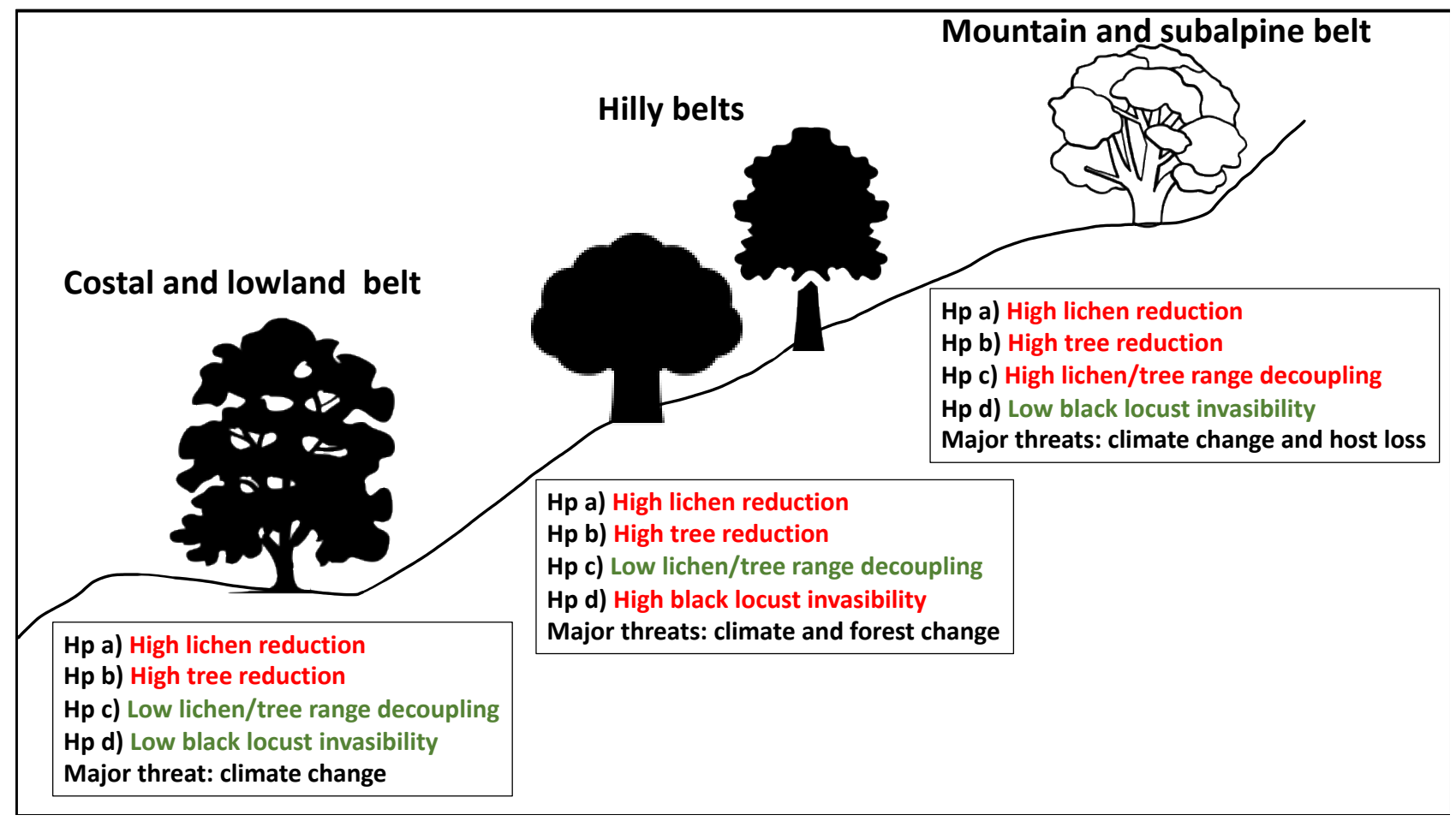


Juri Nascimbene: Conceptualization, Methodology, Investigation, Writing - Original Draft, Writing - Review \& Editing, Data Curation

Renato Benesperi: Conceptualization, Methodology, Investigation, Writing - Review \& Editing, Data Curation

Gabriele Casazza: Formal Analysis, Writing - Review \& Editing

Alessandro Chiarucci: Supervision, Conceptualization

Paolo Giordani: Conceptualization, Methodology, Investigation, Formal Analysys, Writing - Original Draft, Writing - Review \& Editing, Data Curation 


\section{Declaration of interests}

$\bigotimes$ The authors declare that they have no known competing financial interests or personal relationships that could have appeared to influence the work reported in this paper.

$\square$ The authors declare the following financial interests/personal relationships which may be considered as potential competing interests: 


\section{Graphical abstract}

\section{Highlights}

Climate change may directly and indirectly impact species distribution ranges

We tested direct and indirect effects of climate change on the epiphytic lung lichen

We used species distribution modeling for the lung lichen and host tree species

Range reduction of the lung lichen is coupled with a co-reduction of its host trees

Lung lichen range reduction is exacerbated by the spread of the alien black locust 